\title{
THE USE OF ALUMINIUM LINE WIRE AND SOME CONSTANTS FOR TRANSMISSION LINES.
}

\author{
BY F. A. C. PERRINE AND F. G. BAUM.
}

Until the present time, discussions of the use of aluminium wire in line construction have been devoted to a consideration of the relative prices of copper and aluminium wires, the conductivity, tensile strength and other proportions of the alnminium wire being only considered as determining its relative price. During the past year the manufacturers of aluminium have demonstrated their ability to sell this wire at a price well below twice the price of copper per pound, and in consequence the new material has forced itself upon our notice and has demanded that we consider carefully all of its properties independent of any consideration of price. Having recently been forced into the purchase of a considerable amount of this wire by reason of the high price of copper and the low price of aluminium, the writers have made a careful study of the wire supplied, and now present the results obtained in hope that they may be of service to other engineers.

Some of these results have already been published, ${ }^{1}$ but in these publications there have been so many misprints that it seems advisable to present the whole matter anew. The line for which this wire was purchased is about forty-three miles in length, and the country through which it runs varies in elevation from about one hundred feet above the sea level to at least two thousand feet; one-half lying in almost a straight line through

1. Tests and Calculations on a Forty Mile Aluminium Transmission Line. F. A. C. Perrine, Pacific Coast Transmission Association. 
a country almost level, while the remainder is orer the mountains, through which the line runs almost straight, surmounting high hills and descending into deep gulches. In some cases the lengths of the poles were proportioned to decrease the vertical line deflection, but as an accurate preliminary survey was not available, much less grading of poles was possible than would have been desirable. This defect in pole setting was largely counteracted in the wire stringing by the drawing of a number of spans at one time, so that at depressions and elevations there was very little up or down strain put on the wire when it was tied to the insulators. The standard pole used was of square sawn redwood, thirty feet in length, seven inches square at the top, and tapering to twelve inches square at the butt, or about eleven inches at the ground line five feet above the butt. Each pole was gained for three cross-arms $20 \frac{1}{2}$ inches on centers, the gains being cut $\frac{3}{4}$ inch deep, into which the cross-arms were bolted by single $\frac{5}{8}$ inch through bolts. The arms themselves were $4 \times 4$ inch Oregon pine bored for two pins each, the top and bottom arms being three feet in length and the center arm four feet. The wires on this system of construction are arranged in a hexagon, each side being 24 inches in length.

This system of construction presents some advantages for three-phase working at high voltages for long lines, especially where the two sets of circuit are to be operated from the same bus bars. If both of the wires on each arm are at the same potential, the arrangement of each circuit is that of an equilateral triangle, each side being 41 inches, while the minimum distance for leakage between any two wires of different phases is 36 inches of cross-arm and 20 inches of pole, while the length of the longest arm necessary is much less than that in any other system of construction; the pole head is symmetrically loaded, and for these reasons the pole construction is exceptionally stable under all stresses.

The insulators used were a flat topped glass, triple petticoat type, about five inches in height and seven inches in diameter, with a wire groove of about .35 inches radius. The insulators are supported by eucalyptus pins of a length to give a distance of four inches between the bottom of the insulator petticoat and the cross-arm, eucalyptus wood having been used on account both of its availability in California for a special pin, and on account of its great strength, which is of extreme importance 
in the construction of pins of such length. ${ }^{1}$ For further insulation and preservation, the cross-arms used were creosoted by a treatment in which the timber was at first dried carefully and then injected with ten pounds of dead oil of coal tar to the cubic foot, an operation requiring approximately thirteen hours for its completion, while the pins were boiled at a temperature of about $225^{\circ} \mathrm{F}$. for about eight hours in a compound of coal tar and asphaltum, a treatment which gave a better external surface than the creosote. This latter coating did not penetrate the wood materially, but after experimenting extensively with this wood at temperatures up to $225^{\circ} \mathrm{F}$. and pressures up to 160 pounds per square inch without effecting any appreciable penetration of this wood, either with creosote or other extremely fluid materials, all idea of the use of a penetrating compound was abandoned, and an endeavor made to obtain a coating which would provide the most complete external protection.

On this line as erected, the arms were braced by a bent angle iron brace, but this precaution seems now to be entirely unnecessary, and a subsequent line belonging to the Yuba Power Co., erected on much the same plan, is not braced at all. For arms of over five feet in length a brace is certainly advantageous, though it is the opinion of the writers that for high potential service the braces should be of wood mortised into the crossarms and nailed to the pole face.

The above complete physical details of the construction are unnecessary for the discussion of aluminium line wire, though it is believed that its stability when erected depends upon a careful study of all such conditions.

The line as erected carried only four wires arranged on the top and bottom cross-arms, thus taking their location at the corners of a rectangle $24^{\prime \prime}$ on the short side and $41^{\prime \prime}$ on the long side. This arrangement was adopted for the purpose of making temporary use of some two-phase machinery which was in place and underloaded, allowing certain new customers to be taken on quite a year in advance of the contemplated completion of a three-phase plant for which the pole line was really designed.

It was at first feared that this arrangement of the wires would result in inductive disturbances between the phases, as the wires

1. Tests of a considerable number of pins made of eucalyptus, oak and locust show that the eucalyptus has about 20 per cent. more strength than locust and 30 per cent. more than oak. 
took their position's in the diagonally opposite corners of a rectangle, in place of the corners of a square, as is necessary for complete absence of mutual induction, but the anticipated trouble was not found. Careful measurements were made with one phase short-cireuited and the other carrying about 20 amperes with a periodicity of 60 cycles per second, both with a Weston 75-volt voltmeter and a Rowland electro-dynamometer, with the result that no deflection was observable on the voltmeter, while the current read on the electro-dynamometer amounted to only about .001 ampere, the resistance of the dynamometer being $25 \mathrm{ohms}$ and of the line $90 \mathrm{ohms.} \mathrm{Only} \mathrm{one}$ additional question of installation needs attention, which is the presence on the tops of the poles of a barbed wire stapled to the wood of the pole and grounded at every fourth pole by a galvanized iron wire leading down along the pole and soldered to an iron plate 18 inches square and $\frac{1}{8}$ inch thick, set in the pole hole immediately under the foot of the pole itself. This wire was intended as a lightning guard, and it has apparently done very effective service in discharging the line in all weather.

The wire used was intended to be equal to $\mathrm{No} .3$ B and s copper wire in its electrical resistance, and the manufacturers were required to furnish this conductivity in a wire not weighing more than 420 pounds per mile. All the wire supplied was carefully inspected by Dr. A. E. Kennelly, and his reports give the following averages for the total quantity:-

Diameter.......................... 293.9 mils

Wt. per mile..................... $419.4 \mathrm{lbs}$.

Resistance per mil foot..................... $17.6 \mathrm{ohms}$ at $25^{\circ} \mathrm{C}$.

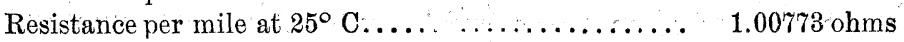

Conductivity compared with copper............. 59.9\% by dimension

Tensile strength of wire $\ldots \ldots \ldots \ldots \ldots \ldots \ldots \ldots \ldots 1549 \mathrm{lbs}$.

No. of twists in six inches for fracture. . . . . . . . 17.9

Tensile strength per square inch................32898

Comparing this with copper it is seen that this wire-is approximately the same as copper in the following sizes :-

Size of aluminium wire $=$ No. 1 B \& S copper
Resistance of " " $"=$ No. 3 " $"$ "
Tensile strength " " $=$ No. 5 " $"$ " $=$ No.6 " 6
Weight of

Therefore on the basis of the same conductivity the aluminium compares with copper as follows :- 
Diameter for the same conductivity 1.27 times copper

$\begin{array}{llllll}\text { Area } & \text { " “ } & \text { " } & 1.64 & \text { " } & \text { " } \\ \text { Tensile strength } & \text { " } & \text { " } & .629 & \text { " } & \text { " } \\ \text { Weight } & \text { " } & \text { " } & .501 & \text { " } & \text { " }\end{array}$

The mechanical properties of this wire present eome well marked characteristics. In the first place, the number of twists necessary for fracture varies considerably, although the ductility test of wrapping six times around its own diameter, unwrapping and wrapping again is well sustained. This irregularity in the twisting test is generally a mark of impurity in wire, but we know so little as yet of the exact characteristics of aluminium in particular, and the twisting test is in general so unreliable that it is unsafe to base any exact statement on this one test, particularly as the same after erection proved reliable. In carefully performing the test for tensile strength no exact point could be assigned for the elastic limit, as the metal seemed to take a permanent set almost from the first, but at a stress of from 14,500 pounds to 17,000 pounds per square inch, there is a marked increase in the permanent set which indicates that the safe working load lies somewhere in this region. In this the characteristics of the aluminium do not differ materially from those of copper or other similar metals, and while this is a disadvantage it is not a singularity.

The fact that the wire will permanently elongate if seriously strained, makes it necessary to use the utmost care in the erection of lines, and also the known high coefficient of expansion with temperature changes taken in conjunction with this property renders care in line stringing especially important and difficult.

For the purpose of ascertaining exactly what were the changes with temperature that might be anticipated, the Pittsburg Reduction Company undertook a series of experiments by means of the observation of 200 feet spans of wire at temperatures varying between $6^{\circ} \mathrm{F}$. and $55^{\circ} \mathrm{F}$, and at the same time the authors carried on a similar series of experiments on a 150 -feet span at the Leland Stanford, Jr. University in which the temperatures varied between $20^{\circ} \mathrm{F}$. and $80^{\circ} \mathrm{F}$. From the results of these experiments a coefficient of expansion with temperature was obtained, which was used in calculating sets of tables for the instruction of the line foreman which gave the tensions and deflections at the different temperatures encountered. These tables were calculated by use of the ordinary approximate formula for the 
tensions and deflections of a suspended wire, and the method used for obtaining the coefficient of temperature expansion removes the usual objection to the formulæ that they do not take into account the elasticity of the wire itself, which produces serious errors if an attempt be made to use the true coefficient of linear expansion by changes of temperature. In fact, the coefficient of linear expansion obtained from these experiments is less than one-half the value of the true coefficient of linear temperature expansion, but its use is justified by the fact that the tables as calculated have been frequently verified experimentally, both at the testing stations and in the field, while the line was being strung. A comparison of the calculated and observed results obtained by the Pittsburg Reduction Co. is given below in Table No. I. As a result of these tests the abovementioned company have issued a table of deflection tensions and temperatures which is given in Table No. II.

TABLE I.

Comparison of Observed and Calculated Deflections of Aluminium WIRE.

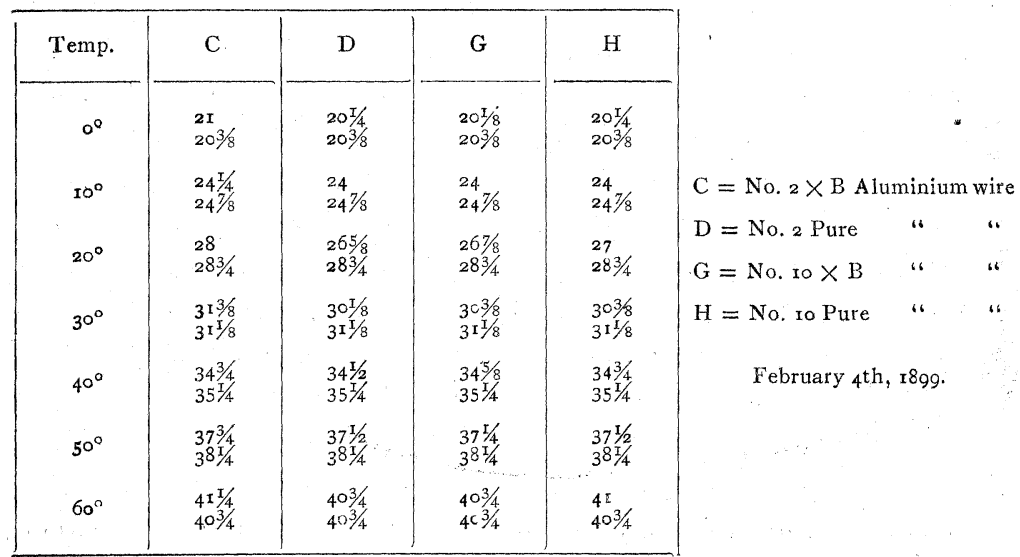

Upper figure is the Observed Deflection.

Lower " " "Calculated "

From the results of the experiments made at the Stanford University a table was calculated in accordance with which the line under discussion was strung. Table No. III.

Attention must be called to the fact that while the minimum temperature given in the table used in California is $+20^{\circ} \mathrm{F}$, 


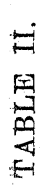

.

.

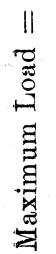

is

窇

2

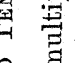

क. 응

这

II

Us

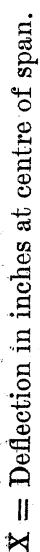

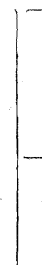

\begin{tabular}{|c|c|c|c|c|c|c|c|}
\hline \multirow{2}{*}{$:$} & $x$ & م్రం & $\underset{\sim}{+\infty+\infty}$ & 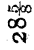 & 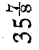 & 番+4 & 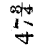 \\
\hline & $\sim 2$ & 号 & 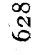 & חר & ‡ & ஜे & 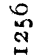 \\
\hline & $x$ & +్రు & $\stackrel{\text { oft }}{\mathrm{N}}$ & $\stackrel{\mathrm{N}}{\mathrm{H}+4}$ & $\frac{-1+1}{m}$ & rto & 筞 \\
\hline
\end{tabular}

$\stackrel{\circ}{\infty}$

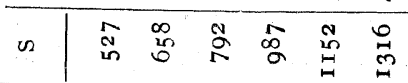

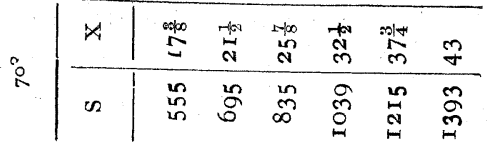

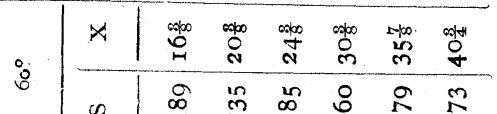

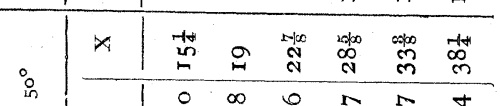

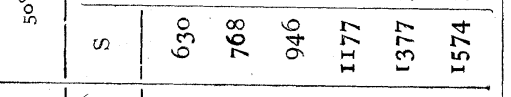

\begin{tabular}{|c|c|c|c|c|c|c|}
\hline$\not$ & $\stackrel{-1 \infty}{ \pm}$ & $\stackrel{20}{=}$ & $\frac{+\infty}{N}$ & : & 盀 & \\
\hline
\end{tabular}

द घ

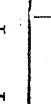

\begin{tabular}{|c|c|c|c|c|c|c|c|}
\hline \multirow{2}{*}{$\stackrel{\circ}{\circ}$} & $x$ & $\underset{n}{-1 \infty}$ & 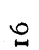 & 离 & ন & - & $\stackrel{+\infty}{m}$ \\
\hline & 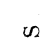 & $\vec{\infty}$ & $\stackrel{m}{m}$ & 워 & $\&$ & $\stackrel{p}{\circ}$ & 요 \\
\hline
\end{tabular}

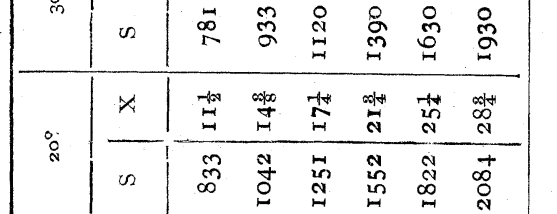

\begin{tabular}{|c|c|c|c|c|c|c|c|}
\hline & $x$ & $\stackrel{0}{0}$ & 跑 & 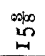 & $\stackrel{+\infty, \infty}{\infty}$ & 에레 & $\stackrel{+N o \infty}{\stackrel{N}{N}}$ \\
\hline & is & 8 & O & $\frac{8}{8}$ & $\begin{array}{l}\infty \\
\stackrel{\infty}{\infty} \\
\end{array}$ & ఫ্ & $\stackrel{\overbrace{}}{q}$ \\
\hline
\end{tabular}

\begin{tabular}{|c|c|c|c|c|c|c|c|}
\hline \multirow{2}{*}{$\therefore$} & $\rtimes$ & $-\infty$ & 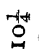 & 幽 & 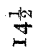 & 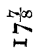 & 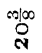 \\
\hline & $\Omega$ & $\stackrel{D}{\stackrel{D}{W}}$ & 胥 & 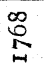 & $\begin{array}{l}\text { 字 } \\
\text { a }\end{array}$ & $\underset{\substack{\text { R } \\
\text { N }}}{ }$ & 离 \\
\hline \multirow{2}{*}{$\stackrel{0}{0}$} & $x$ & oidn & ה & $\underbrace{\infty}_{\infty}$ & $\stackrel{-\infty}{\square}$ & 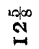 & 装 \\
\hline & $\Omega$ & $\underset{\sim}{\stackrel{\circ}{\circ}}$ & $\begin{array}{l}m \\
\infty \\
\text { N }\end{array}$ & 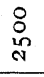 & $\stackrel{\infty}{\tilde{ల}}$ & 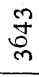 & $\begin{array}{l}\stackrel{8}{\circ} \\
\stackrel{4}{+}\end{array}$ \\
\hline \multirow[t]{3}{*}{ : } & $x$ & 아하 & - & Hed & allos & m & $\stackrel{1060}{\leftarrow}$ \\
\hline & (2) & 永 & $\begin{array}{l}\text { 离 } \\
\text { 에 }\end{array}$ & 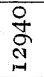 & 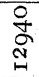 & 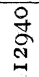 & 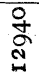 \\
\hline & : & $\infty$ & 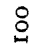 & ్ㅗㄱ & $\stackrel{\circ}{\stackrel{ }{6}}$ & $\stackrel{2}{5}$ & 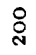 \\
\hline
\end{tabular}

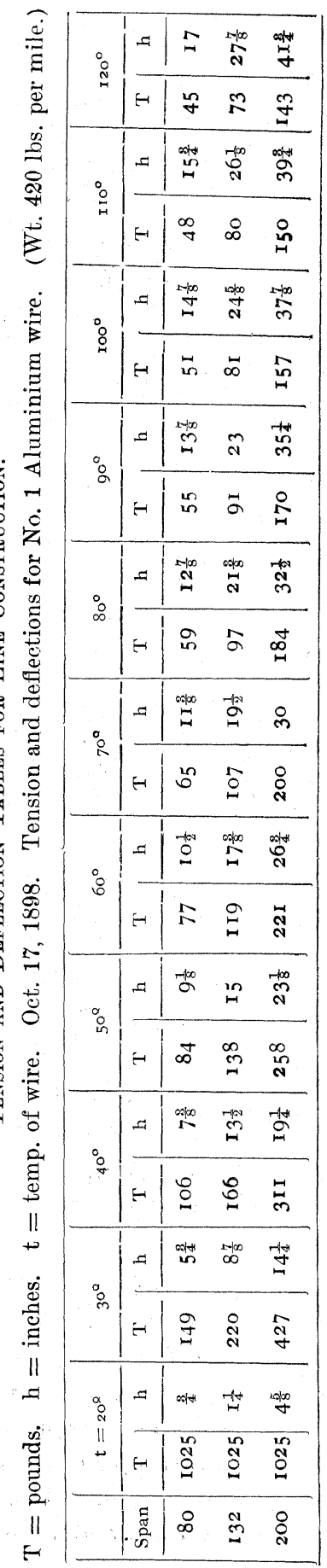


that given by the Pittsburg Reduction Co.is $=-20^{\circ} \mathrm{F}$. These different minimum temperatures are made necessary by the conditions under which the wires are to be strung, and they indicate merely the starting points of the tables; counting from this point it is seen the maximum difference in deflection for the two tables is $4 \frac{3}{4}$ inches for the 200 -feet span at a temperature rise of 100 degrees above the minimum. While this difference in deflection is not beyond the errors in the thermometer and deffection observations in the field, it is the belief of the writers that Table No. II is the more reliable on account of the fact that it was deduced from a larger series of observations made under the more favorable circumstances.

A copy of Table No. III together with the following instructions was issued to the line foreman, who was also provided with a thermometer, a dynamometer and a pair of targets for measuring the deflections.

Instructions to line foreman in stringing wires:-

1. All spans are to be strung with deflections and tensions as specified in table.

2. Up and down hill spans to be sprung to correspond with level spans. In case level spans cannot be used, then employ dynamometer, and ease all wires over cross-arms.

3. All ties are to be made at one time by signal.

4. All ties are to be made by crossing wires around insulator serving three times around wire, and twisting behind insulators; the ends of the tie-wires are not to be cut, but bent back toward insulators.

5. Tie all wires on the outside of the insulators, except at corners where all are to be tied so that the strain is against the insulator.

6. Joints are to be made by means of sleeves twisted two and a half times, the ends of the wires being given one turn by hand around the wire. No tools are used, except in twisting the sleeves and cutting off the ends of the wires. Before inserting the wire in the sleeve, the ends of the wire must be roughened by draw filing.

7. Barbed wire is to be laid along the roofs of the poles and held by three staples driven in tight, but without kinking the wire. Ground wires are to be soldered to the barbed wire and at the bottom of the pole to the wire leading from the ground plate. All soldering acids must be carefully washed away after the soldering is done. 
8. Beginning between poles one and two, all wires are to be barreled by shifting one pin, and same to be repeated between poles 21 and 22 and 41 and 42 , and so on. Barreling always in the same direction of twist every twenty poles. A record must be kept of the location of every wire and every pole.

General Caution.-The greatest care must at all times be taken against kinking or scarring the wire; wherever the wire is accidentally kinked or scarred it must be cut and spliced.

The targets mentioned above consisted of light sheet iron strips about two feet long and two inches wide, with an aluminium hoop bent into an eye at the top, by means of which they could be hung from the line wire. These targets were painted in three or four colors, with bands one inch wide. In use, the captain of the linemen would hang his target on the wire to which a man on the next pole had also hung a target; then, as the wire was being pulled into place, he would sight from a band on his target to the same band on the adjacent target, and when the wire came into line with these two bands the signal would be given for all the linemen to tie at once. As a result of this method of stringing, an exceedingly uniform line and one strong in accordance with the temperature was obtained.

One of the most serious problems in connection with the use of aluminium is in the choice of a proper joint. This metal is so highly electro-positive that it is unsafe to expose it to the elements in contact with any other material, as electrolytic corrosion is almost sure to follow such construction. Many of the failures which have been reported of this metal have been due to a neglect of this fact; as notably in the case of the plates on the yacht Defender, where the plates have been corroded at the contact with the bronze rivets used in fastening them to the frame. Whenever this metal is soldered or used in contact with any other metal, the joint should be thoroughly waterproofed to prevent such action. After discussing many joints, it was finally determined to abandon any attempt to solder or clamp the wire in any manner, and the joints were made by slipping the ends of the wire into an oval aluminium tube about nine inches long, which was then twisted with a pair of clamps similar to those employed in twisting the McIntire connector. After twisting the tube a turn was taken by hand of the loose ends and the wire cut off close. The joint produced proved practically equal to the original wire in both tensile strength and electrical conductivity. 
This wire was erected during the winter of 1898-99, which was an unusually open winter over the whole State of California, allowing practically continuous construction work, though the temperature varied all the way from about $30^{\circ} \mathrm{F}$. to $80^{\circ} \mathrm{F}$. at times when the wire was being strung. After it was finally erected it remained about three months on the poles before the machinery was delivered and put in place. During the first month of that time three breaks occurred which were all apparently due to flaws in the material, but after these breaks were repaired the line wire gave absolutely no trouble whatever, though various accidents occurred to other parts of the construction. Many insulators were shot at and broken, bale wire and bale rope was thrown over the line, a twig short-circuited one phase and fell down burned, a large bird was killed by contact with the wires, and finally several porcelain insulators with porcelain pins were broken off and hung suspended by the wire. In January and February of the present year this whole line was taken down to give place to a much heavier one of the same material, an opportunity for such a total change having been found after the total destruction of the power-house by fire last November.

During the past two years other lines of aluminium wire have been erected on the Pacific coast, all but one of which have given a considerable amount of trouble from causes that are not entirely apparent.

One line in Nevada County, erected at about the same time as that we have been describing, and for which the wire was of practically the same lot, has given no trouble whatever.

The power transmission lines of aluminium wire about Seattle have broken a few times, but have not given serious trouble. The breaks in this line, so far as the writers have been informed, seem to have been due to not allowing enough sag at the higher temperatures, and a consequent overstraining of the wire in cold weather.

The most serious difficulties have been encountered by the telephone company in Washington and Oregon and by the Yuba Power Co. In all of these cases it seemed almost impossible to keep the wires on the poles in certain sections, and in these sections the lines have been finally taken down and replaced by other wire of either copper or aluminium. The writers have examined many breaks from these lines, and would judge, from the 
appearance of the fracture, that the cause, whatever it may be, was similar. In those breaks there are many small flaws, but by far the greatest majority are clear, sharp fractures, with but a slight reduction of area, and that entirely on one side, a break very characteristic of improperly mixed and brittle alloys. Partially from the appearance of the fracture and partially from the facts that the breaks occur only in certain sections of the line, the writers are of the opinion that this trouble is due to the presence of impurities in the material. This view is strengthened by the fact that when measurements were made on the line of the Yuba Power Co., the resistance of the whole line was found to be 10 per cent. greater than it should have been if it were made of the quality of material described in the earlier part of this paper. Furthermore, in one-half of this line there were no breaks at all due to defects in the wire itself.

As a general conclusion, it is the opinion of the writers that aluminium can be safely used in place of copper where the proper precautions are taken in inspecting the wire before it is erected, and in erecting it with due consideration of its peculiar properties of low and indefinite elastic limit, high coefficient of temperature expansion and active electrolytic power.

Indicating our faith in this opinion, it may be noted that for the new line soon to be erected an aluminium strand $\frac{8}{4}$ inch in diameter has been ordered. This strand will be spliced with aluminium sleeves, and in the whole construction about one million pounds of aluminium will be employed.

Experimental and Mathematical Determination of Line

Constants.

Opportunity was given to test the line described above and also another aluminium line 62 miles in length,No. 4 B. and s. wire. These lines were tested for capacity, self-induction, mutual induction, ohmic resistance and insulation.

As there has been some difference of opinion among electrical engineers as to the charging current or capacity current of a three-phase line, great care was taken to accurately determine the capacity of a line when arranged, as is usual in practice, with the wires on the corners of an equilateral triangle. If the line capacity may be considered as connected between the wires $\Delta$, the charging current in one wire would be $\sqrt{3}$ times the charging current of a single-phase line for the same voltage and 
distance between wires. On the other hand, if the line capacity is star connected, the charging current of one wire would be $\frac{2}{\sqrt{3}}$ times the charging current of a single-phase line for the same voltage and distance between wires. To determine which of the above is the correct assumption, it was only necessary to charge the three wires with three-phase potential and measure the current in one wire, then disconnect one wire from the potential source and read the ammeter again. All the measurements indicated that the line capacity is to be considered as star connected.

The method used to determine the line capacity was to insulate one end of the line and to charge the line with three-phase potential from the other end. To measure the potential applied, a Weston 150-volt voltmeter, which was checked before and after the experiments, was used. To measure the current a special Rowland electro-dynamometer was used. The instrument was calibrated and frequently checked in the position used, by sending a current through it and a known non-inductive resistance by a known potential difference. The leakage current over the insulators could be neglected. For convenience, safety, and to eliminate errors, a low potential, 130 to 200 volts, was applied to the line and the ammeter connected directly in series with one line wire. The results obtained for the capacity of a threephase line experimentally agree with those obtained by calculation. No disagreement with the conclusion has yet come to our notice, although the charging current has been subsequently observed with voltages as high as 25,000 , and no disagreement is expected in the line at present being erected; the potential of the line is to be above 40,000 volts between wires, the wires being $\frac{8}{4}$ " aluminium cables with $42^{\prime \prime}$ between centers.

The method used in making these calculations-which is here given-is believed to have an advantage of simplicity over the method due to Oliver Heaviside, now generally used for calculating the electro-static capacity of transmission lines. It will be found to give a solution for all cases found in practice with little labor.

In calculating the capacity of a condenser, the plates are assumed charged with equal and opposite quantities of electricity and the potential difference between the plates is calculated; 
the capacity of the condenser being defined as the ratio of the quantity of electricity on one of the plates to the difference of potential between them.

Take, first, the simple case of two wires suspended in free space, Fig. 1. Charge wires with $+Q$ and $-Q$ units of electricity per unit of length of line. The potential difference between wires

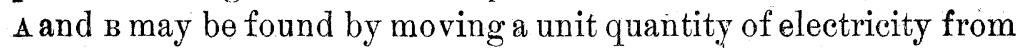
the surface of $A$ to the surface of $\mathrm{B}$, or, since there is a plane of zero potential midway between $\mathrm{A}$ and $\mathrm{B}$, we may move the unit charge from o to the surface of в. This will give the capacity between B and the mid-plane.

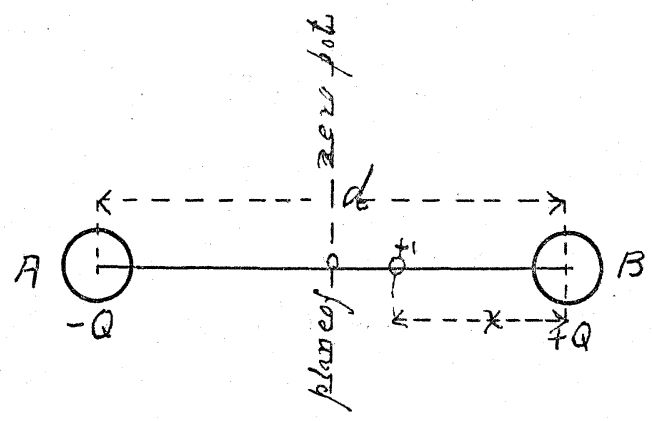

Fig. 1.

The force acting on the unit quantity at the distance $\mathrm{x}$ from $B$ is

$$
F=-\frac{2 Q}{x}-\frac{2 Q}{d-x}
$$

Multiply by $-d x$ and integrate between the limits $x=\frac{d}{2}$ and $x=r(r=$ radius of wire $)$.

We get

$$
\begin{aligned}
& \quad V=[2 Q \log x]_{r}^{\frac{d}{2}}-[2 Q \log (d-x)]_{r}^{\frac{d}{2}} \\
& =2 Q\left(\frac{d}{2}\right)-2 Q \log (r)-2 Q \log \left(\frac{d}{2}\right)+2 Q \log (d-r) \\
& =2 Q \log \left(\frac{d-r}{r}\right)
\end{aligned}
$$


Or, since for ærial lines $r$ is small in comparison with $d$, we have $V=2 Q \log \left(\frac{d}{r}\right)$, and the capacity in electro-static units between $\mathrm{B}$ and the mid-plane per unit length of line is

$$
C=\frac{1}{2 \log _{\mathrm{e}}\left(\frac{d}{r}\right)}
$$

The total potential between the two wires is

$$
V=4 Q \log _{\mathrm{e}}\left(\frac{d}{r}\right)
$$

and therefore the capacity between the wires

$$
C_{\mathrm{ab}}=\frac{1}{4 \log _{\mathrm{e}}\left(\frac{d}{r}\right)}
$$

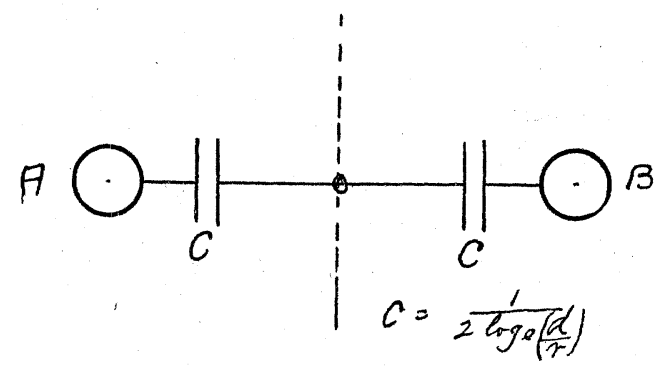

FIG. 2.

It will simplify matters some when we come to multiphase circuits to consider the capacity $C_{\mathrm{ab}}$ between the two wires as made up of two capacities, $C$ equation (3), connected in seriee from $\mathrm{A}$ to $\mathrm{B}$, as in Fig. 2.

From the above proof it follows that in calculating the capacity of different systems the following general proposition may be made regarding the work done in moving unit quantity of electricity from one point of an electrostatic field to another, the field being due to a charged wire, the wire being considered infinite in length :

The work done in moving unit quantity of electricity from one point of an electric field to another against the force due to 
a charged wire is equal to twise the quantity of electricity on the wire times the logarithm of the ratio of the initial to the final distance of the unit charge from the wire. If there are several wires in the field the algebraic sum of all the terms formed as above will give the work; the sign of each term is

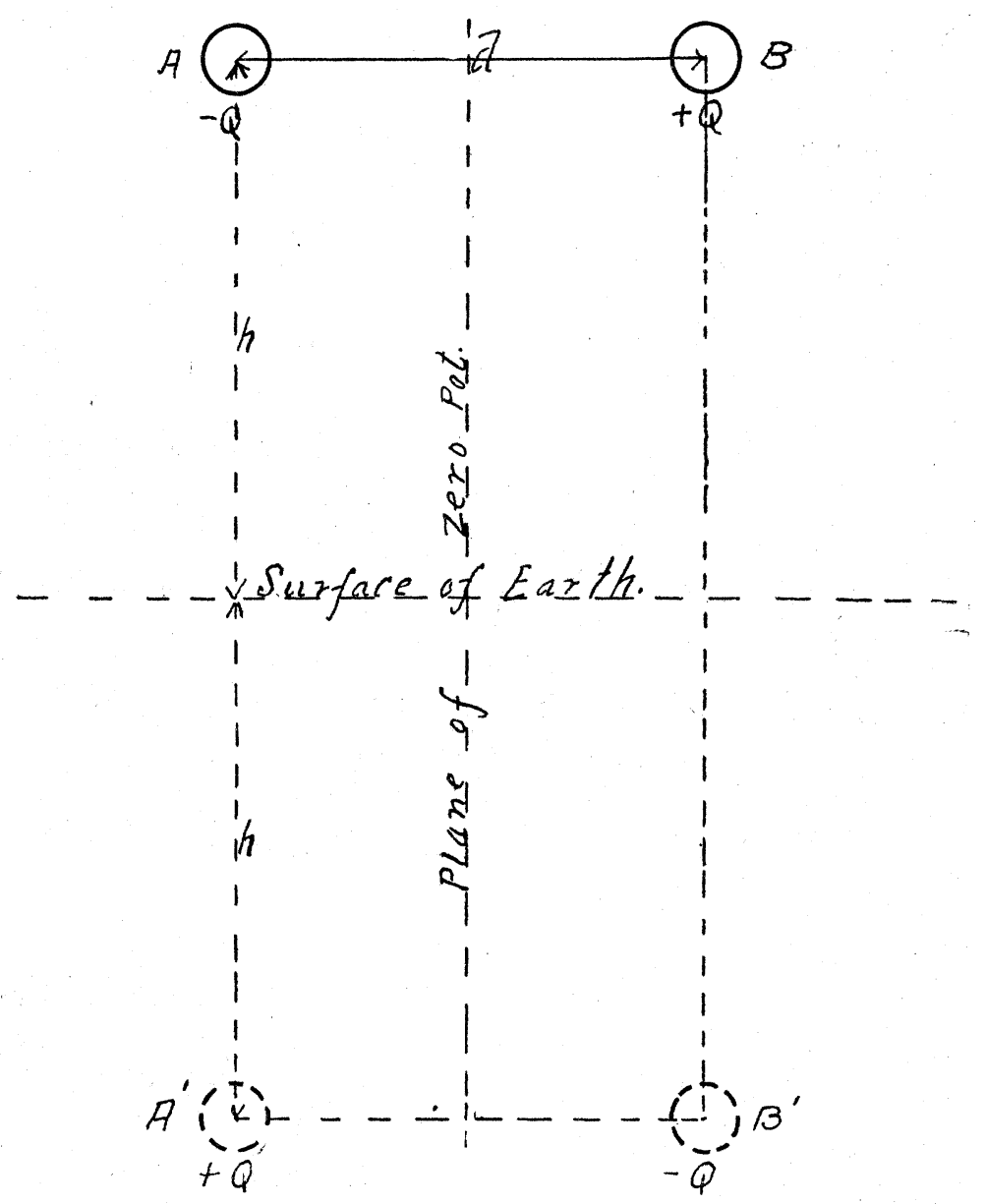

Fig. 3.

determined by the sign of the quantity of electricity on the wire in question.

As an illustration of the above let us find the effect of the earth on the capacity of two wires distanced $h$ above its surface, Fig. 3. Move the unit quantity of electricity from the surface of $A$ to $B$. 
The work done against the force due to $\mathrm{A}$ is

$$
-2 Q \log \left(\frac{r}{d}\right)=+2 Q \log \left(\frac{d}{r}\right){ }^{*}
$$

the work done against $\mathrm{B}$ is

$$
+2 Q \log \frac{d}{r}
$$

the work done against $A^{1}$ is

$$
+2 Q \log \left(\frac{2 h}{\sqrt{(2 h)^{2}+(d)^{2}}}\right)=-2 Q \log \left(\frac{\sqrt{(2 h)^{2}+d^{2}}}{d^{2}}\right)
$$

the work done against $\mathrm{B}^{1}$ is

$$
-2 Q \log \left(\frac{\sqrt{(2 h)^{2}+d^{2}}}{d^{2}}\right)
$$

The potential between $A$ and $B$ is the sum of the above four terms; this gives us

$$
\begin{gathered}
V=4 Q\left[\log \left(\frac{d}{r}\right)-\log \left(\sqrt{1+\left(\frac{d}{2 h}\right)^{2}}\right],\right. \text { giving } \\
C=\frac{1}{4\left[\log \left(\frac{d}{r}\right)-\log \left(\sqrt{\left.1+)_{2 \bar{h}}\right)^{2}}\right.\right.}
\end{gathered}
$$

As will be seen by comparing with equation (4) the influence of the earth on the capacity of ærial lines may be generally neglected.

Whenever the wires of the circuit are symmetrically placed with respect to a plane, this is a plane of zero potential; whenever the wires are placed symmetrically with respect to a line, this will be a line of zero potential. It is assumed in the above that there are no other wires very near the wires of the

* This should be $-2 Q \log _{\mathrm{e}}\left(\frac{d-r}{r}\right)$, but $r$ may always be neglected in comparison with $d$ for ærial lines. This assumption is made throughout the paper. 
circuit. In such cases-practically all transmission lines-it is usually simpler to calculate the capacity between one wire and the plane of zero potential or between one wire and the line of zero potential.

Three-phase transmission lines are usually arranged with the wires on the corners of an equilateral triangle, this arrangement gives a line of zero potential at the center of the triangle. For this case we may calculate the capacity between one wire (A) and the center point o, Fig. 4. The instantaneous quantities of electricity on wires A, в and c will be $Q \sin \omega t, Q \sin \left(\omega t-120^{\circ}\right)$ and $Q \sin \left(\omega t-240^{\circ}\right)$ respectively. With the aid of the
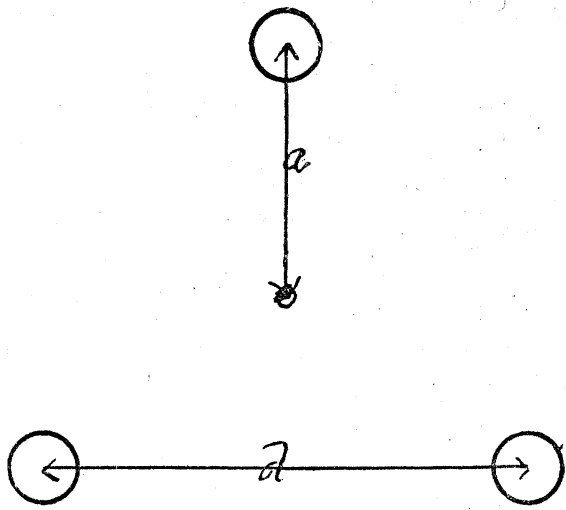

Fig. 4.

above corollary, calculate the work done in moving unit charge from $o$ to $\mathrm{A}$.

This gives

$$
\begin{array}{r}
V=2 Q \sin \omega t \log \left(\frac{a}{r}\right)+2 Q \sin \left(\omega t-120^{\circ}\right) \log \left(\frac{a}{d}\right)+ \\
2 Q \sin \left(\omega t-240^{\circ}\right) \log \left(\frac{a}{d}\right)
\end{array}
$$

$=2 Q \sin \omega t \log \left(\frac{d}{r}\right) ;$ and the capacity per unit length of line is

$$
C=\frac{1}{2 \log _{\mathrm{e}}\left(\frac{d}{r}\right)} ; \text { the same result for в and } \mathrm{c} \text {. }
$$

The result gives the capacity arranged as in Fig. 5, which agrees with experiment. 


\section{TABLE IV.}

Capacity in Micro-Farads and Charg. Cur. per mile of circuit for three-phase Line E.M.F. -10.000 volts.

60 P.P.S.

\begin{tabular}{|c|c|c|c|c|c|c|c|c|c|}
\hline $\begin{array}{c}\text { Size } \\
\text { B. \& S. }\end{array}$ & $\begin{array}{l}\text { Diam. } \\
\text { in inch. }\end{array}$ & $\begin{array}{c}\text { Distance } \\
d \\
\text { in inch. }\end{array}$ & $\begin{array}{c}\text { Capacity } \\
\text { C } \\
\text { M. F. }\end{array}$ & $\begin{array}{l}\text { Charg. } \\
\text { cur. in } \\
\text { Amperes }\end{array}$ & B. \&ize $\mathrm{S}$. & $\begin{array}{l}\text { Diam. } \\
\text { in inch. }\end{array}$ & $\begin{array}{c}\text { Distance } \\
d \\
\text { in inch. }\end{array}$ & $\begin{array}{l}\text { Capacity } \\
\text { in } M . F .\end{array}$ & $\begin{array}{l}\text { Charg. } \\
\text { cur. in } \\
\text { Ampere: }\end{array}$ \\
\hline \multirow[t]{4}{*}{0000} & .46 & 12 & .0226 & .0492 & 4 & .204 & 12 & .01874 & .0408 \\
\hline & & I8 & .0204 & .0447 & & & $x 8$ & .01726 & .0377 \\
\hline & & 24 & .01922 & .0418 & & & 24 & .01636 & .0356 \\
\hline & & $4^{8}$ & .01474 & $.036_{4}$ & & & 48 & .01452 & .0317 \\
\hline \multirow[t]{3}{*}{000} & .41 & 12 & .0218 & .0474 & 5 & .182 & I 2 & .01830 & .0399 \\
\hline & & 18 & .01992 & .0414 & & & 18 & .01690 & .0368 \\
\hline & & 24 & .01876 & .0408 & & & 24 & .01602 & .0349 \\
\hline \multirow[t]{4}{*}{$\infty$} & .365 & $\begin{array}{l}4^{8} \\
12\end{array}$ & $\begin{array}{l}.01638 \\
.0214\end{array}$ & $\begin{array}{l}.0356 \\
.0465\end{array}$ & 6 & .162 & $\begin{array}{l}4^{8} \\
\mathbf{x}\end{array}$ & $\begin{array}{l}.01426 \\
.01788\end{array}$ & $\begin{array}{l}.0311 \\
.0389\end{array}$ \\
\hline & & 18 & .01946 & .0423 & & & 18 & .01654 & $.0_{3} t_{0}$ \\
\hline & & 24 & .01832 & .0399 & ) & & 24 & .01560 & .0342 \\
\hline & & 48 & $.016 c 4$ & .0349 & & & 48 & .0140 & .0305 \\
\hline \multirow[t]{4}{*}{0} & $.3^{25}$ & 12 & .02078 & .0453 & 7 & .144 & 12 & .01746 & $.03^{8} 9$ \\
\hline & & 18 & .01898 & .0413 & & & I 8 & .01618 & .0352 \\
\hline & & 24 & .01642 & .0379 & & & 24 & $.0153^{8}$ & .0335 \\
\hline & & $4^{8}$ & $.0157^{\circ}$ & .0342 & & & $4^{8}$ & .01374 & .0290 \\
\hline \multirow[t]{4}{*}{ I } & .289 & 12 & .02022 & .0440 & 8 & .128 & 12 & .01708 & $.037^{2}$ \\
\hline & & 18 & .01952 & .0403 & & & r8 & .01586 & $.034 \mathrm{I}$ \\
\hline & & 24 & . or 748 & .0380 & & & 24 & .01508 & .0328 \\
\hline & & 48 & .0154 & .0337 & & & 48 & $.0135^{\circ}$ & .0294 \\
\hline \multirow[t]{4}{*}{2} & .258 & 12 & .01972 & $.037^{2}$ & 9 &. $\mathrm{II}_{4}$ & 12 & .01660 & .0364 \\
\hline & & 18 & .01818 & .0305 & & & 18 & .01552 & .0337 \\
\hline & & 24 & . Or7 Io & $.037^{2}$ & & & 24 & .01478 & .0317 \\
\hline & & 48 & .01510 & .0328 & & & 48 & .01326 & .0289 \\
\hline \multirow[t]{4}{*}{3} & .229 & 12 & .01938 & .0421 & IO & .102 & 12 & .01636 & .0356 \\
\hline & & I8 & .01766 & .0385 & & & 78 & .01522 & .0320 \\
\hline & & 24 & .01672 & .0364 & & & 24 & .01452 & .0310 \\
\hline & & 48 & .01480 & .0322 & & & $4^{8}$ & .01304 & .0284 \\
\hline
\end{tabular}

Basis of Table.

$$
\mathrm{C}=\frac{1}{2 \log _{\theta}\left(\frac{d}{r}\right)}
$$

in electro-static units per $\mathrm{cm}$. of circuit.

$$
\mathrm{C}=\frac{0.0776 \times \mathrm{L}}{2 \log _{10}\left(\frac{d}{r}\right)},
$$

in micro-farads bet. one wire and neutral point for $\mathrm{L}$ miles of circuit.

$$
\text { Charg. cur. per wire }=\frac{E \times C \times 2 \pi \times f}{\sqrt{3} \times 10^{\circ}}
$$

$d=$ distance bet. wires, (inch).

$r=$ radius of wire (inch).

$L=$ length of circuit in miles.

$E=$ E.M.F. bet. wires.

$f=$ cycles per sec.

$C=$ cap. in м. F. bet. one wire and neutral pt.

Charg. cur. three-phase $=\frac{2}{\sqrt{3}}(=15.5 \%) \times$ charg. cur. sing. phase for same $d, r . L$, and $E$. 
If the wires are arranged on a straight line and not transposed, the line of zero potential moves harmonically between the two points midway between the two outside wires. The capacities between any two of the wires may be found by the method given, the unit quantity being moved from the surface of one wire to the surface of the other. If the wires are transposed, the capacity of the line may be approximately determined by adding the capacities of the several sections. The capacity for any arrangement will not differ greatly from that given for the wires arranged as in Fig. 5. Table 4 has been prepared for convenience; the capacity in microfarads and the charging current per mile with 10,000 volts between wires are given for a frequency of 60 P. P. s.

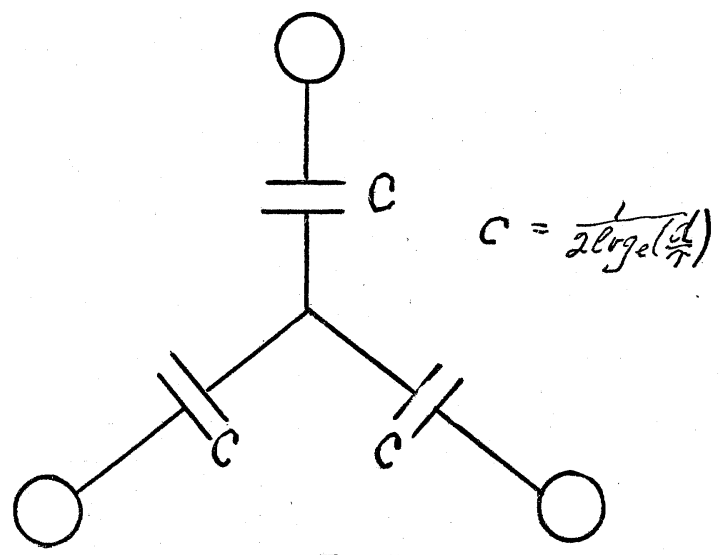

Fig. 5.

The self-induction of the line experimented upon was determined by short-circuiting the line at one end and measuring the current produced by a known potential. The observed result agreed with the caleulated value.

The self-induction of one wire of a three-phase circuit arranged on the corners of an equilateral triangle is usually calculated by assuming the other two wires as a return at a distance $D$. To get the inductive drop between two wires, the self-inductions are combined geometrically. This is correct, but as no mathematical proof has come to our notice, one is here given :

The wires are arranged as in Fig. 4 , the currents in $\mathrm{A}, \mathrm{B}$ and $\sigma$ being $I \sin \omega t, I \sin \left(\omega t-120^{\circ}\right)$ and $I \sin \left(\omega t-240^{\circ}\right)$ 
respectively. The number of lines of force threading A B per unit length of line at time $t$ is

$$
\begin{aligned}
N_{\mathrm{ab}}=2 I \sin \omega t \log \left(\frac{d}{r}\right)+\frac{I \sin \omega t}{2}- \\
{\left[2 I \sin \left(\omega t-120^{\circ}\right) \log \left(\frac{d}{r}\right)+\frac{I \sin \left(\omega t-120^{\circ}\right)}{2}\right] } \\
\quad(\text { Wire o has no effect on looop A B. }) \\
=2 \sqrt{3}\left[\log \left(\frac{d}{r}\right)+\frac{1}{4}\right] I \sin \left(\omega t+\tan ^{-1} \frac{1}{\sqrt{3}}\right)
\end{aligned}
$$

giving for the self-induction of $\mathrm{A}$ B for length of line $\mathrm{L}$

$$
L_{\mathrm{ab}}=2 \sqrt{\overline{3}}\left[\log \left(\frac{d}{r}\right)+\frac{1}{4}\right] \times L
$$

Table 5 gives values for $L_{\mathrm{ab}}$ for one mile of circuit for 66 P. Р. 8 .

The self-induction of one wire considering the return at a distance $d$ is

$$
L_{\mathrm{a}}=2\left[\log \left(\frac{d}{r}\right)+\frac{1}{4}\right]
$$

Equation (7) may be obtained from (8) by combining $L_{\mathrm{a}}$ and $L_{\mathrm{b}}$ geometrically.

If the wires forming the circuit are arranged in a straight line and transposed, each wire taking the center pin for $\frac{1}{3}$ the distance, wire o will have no effect on the loop A B. Arranged in this way the wires A B will be apart distanced $d$ for two-thirds of the length of the line and $2 d$ for the remaining one-third. The self-induction of the loop A в is, then :

$$
L_{\mathrm{ab}}=2 \sqrt{3}\left\{\left[\log \left(\frac{d}{r}\right)+\frac{1}{4}\right] \frac{2}{3} L+\left[\log \left(\frac{2 d}{r}\right)+\frac{1}{4}\right] \frac{L}{3}\right\}
$$

This shows that aside from the question of transposing there is some advantage in arranging the wires on the corners of an equilateral triangle. 
TABLE V.

Inductance per mile of circuit for three-phase system. 60 P. P. s.

\begin{tabular}{|c|c|c|c|c|c|c|c|c|c|}
\hline $\begin{array}{c}\text { Size } \\
\text { B. \& S. }\end{array}$ & $\begin{array}{l}\text { Diam. } \\
\text { in inch. }\end{array}$ & $\begin{array}{c}\text { Distance } \\
d \\
\text { in inch. }\end{array}$ & $\mid \begin{array}{c}\text { Self. Ind. } \\
L_{\text {ab }} \\
\text { Henrys. }\end{array}$ & $\mid \begin{array}{c}\text { Induc- } \\
\text { tance } \\
L \mathrm{ab} \times 2 \pi \\
\times 60 \\
\text { Obms. }\end{array}$ & $\begin{array}{c}\text { Size } \\
\text { B. \& S. }\end{array}$ & $\begin{array}{l}\text { Diam. } \\
\text { in inch. }\end{array}$ & $\begin{array}{c}\text { Distance } \\
\quad d \\
\text { in inch. }\end{array}$ & $\mid \begin{array}{c}\text { Self. Ind. } \\
L_{\mathrm{ab}} \\
\text { Henrys. }\end{array}$ & $\begin{array}{c}\text { lnduc- } \\
\text { tance. } \\
L_{\mathrm{ab} \times 2 \pi} \pi \\
\times 60 \\
\text { Ohms. }\end{array}$ \\
\hline \multirow[t]{4}{*}{0000} & $.4^{6}$ & I2 & .00234 & 0.884 & 4 & .204 & 12 & .00280 & I. 057 \\
\hline & & 18 &. $\mathrm{co2} 56$ & .967 & & & I8 & $.003 \mathrm{CO}$ & T. 133 \\
\hline & & 24 & . $\mathrm{CO} 7 \mathrm{O}^{\circ}$ & 1.015 & & & 24 & $.003{ }^{1} 5$ & I. 189 \\
\hline & & 48 & $.003^{12}$ & I. $x 78$ & & & $4^{8}$ & .00358 & $\mathrm{r} .35^{\mathrm{I}}$ \\
\hline \multirow[t]{4}{*}{000} & $.4 \mathrm{r}$ & I2 & $.0024 x$ & .910 & 5 & .182 & I2 & .00286 & 1.080 \\
\hline & & I8 & $.002 \sigma_{2}$ & .989 & & & 18 & $.003 \mathrm{c}^{2}$ & 1.159 \\
\hline & & 24 & .00277 & 1.046 & & & 24 & $.003^{2} 3$ & 1.220 \\
\hline & & 48 & .00318 & $1.20 \mathrm{I}$ & & & $4^{8}$ & .00356 & I 344 \\
\hline \multirow[t]{4}{*}{ ০o } & $\cdot 365$ & 12 & .00248 & .937 & 6 & .162 & I2 & $.0029 \mathrm{I}$ & 1.098 \\
\hline & & 18 & .00269 & 1.016 & & & 18 & $.003{ }_{3}$ & 1.18: \\
\hline & & 24 & .00285 & I. 076 & & & 24 & .00329 & $1.2+3$ \\
\hline & & 48 & .00330 & 1.246 & & & 48 & .00360 & 1.393 \\
\hline \multirow[t]{4}{*}{0} & .325 & I2 & .00254 & .959 & 7 &. $\mathrm{I}_{44}$ & 12 & .00298 & T.125 \\
\hline & & 18 & .00276 & 1.042 & & & I8 & .00319 & $1.2 \times 4$ \\
\hline & & 24 & .00293 & T. 106 & & & 24 & .00336 & $1.269^{\circ}$ \\
\hline & & 48 & $.0033^{1}$ & 1.250 & & & 48 & .00377 & 1.423 \\
\hline \multirow[t]{4}{*}{ I } & .289 & 12 & .00260 & .983 & 8 & .128 & I2 & .00303 & $\mathrm{I.144}$ \\
\hline & & 18 & $.0028 \mathrm{I}$ & $1.06 \mathrm{I}$ & & & I8 & .00325 & $\mathrm{I} .227$ \\
\hline & & 24 & .00248 & 1.125 & & & 24 & $.0034 \mathrm{I}$ & $\mathrm{I} .288$ \\
\hline & & 48 & $.0033^{8}$ & 1.276 & & & 48 & .00384 & 1.450 \\
\hline \multirow[t]{4}{*}{2} & $.25^{8}$ & 12 & .00267 & 1.008 & 9 & .114 & 12 & .00310 & 1.171 \\
\hline & & 18 & .00288 & I.088 & & & 18 & .00332 & $\mathrm{x} .253$ \\
\hline & & 24 & .00304 & I. 148 & & & 24 & .00348 & 1.314 \\
\hline & & 48 & .00344 & I. 299 & & & $4^{8}$ & .00389 & 1.469 \\
\hline \multirow[t]{4}{*}{3} & .229 & I2 & .00274 & 1.035 & ro & .102 & 12 & .00318 & 1.201 \\
\hline & & I 8 & .00294 & T. IIo & & & I8 & .00340 & I. $2 ? 4$ \\
\hline & & 24 & $.003^{10}$ & I. 77 & & & 24 & .00355 & $\mathrm{I} .34^{\circ}$ \\
\hline & & $4^{8}$ & $.0035 \mathrm{I}$ & I. 335 & & & $4^{8}$ & .00396 & r. 495 \\
\hline
\end{tabular}

Basis of Table.

$L_{\mathrm{ab}}=2 \sqrt{3}\left[\frac{\log \left(\frac{d}{r}\right)}{0.434}+\frac{1}{4}\right]=$ self ind. in C. G. S. units for loo

a. b. (pec. cm.)

$$
L_{\mathrm{ab}}=0.000558\left[2.303 \log _{10}\left(\frac{d}{r}\right)+.25\right] L \text {, in henrys. }
$$

Inductive drop in loop $a b=L_{\mathrm{ab}} \times 2 \pi \times f \times I$.

$d=$ dis. bet. wires (inch).

$r=$ rad. of. wire,

$L=$ length of circuit in miles.

$f=$ cycles per sec.

$I=$ current in one wire.

For self ind. of one wire divide $L_{\mathrm{ab}}$ by $\sqrt{3}$

\section{Regulation of Transmission Lines.}

The question of the regulation of the system for possible power factors is important. Knowing the probable power factor of the load the line-drop may be calculated, thus determining the amount 
of regulation which must be allowed. If there are several substations at different distances from the generating station to be supplied, the regulation to be allowed in each sub-station should be calculated. As the charging current of the line has an important bearing on the regulation of the system this question will be discussed.

At the present time there are two methods for determining the effect of the capacity current of a line on the voltage of the receiver. In the method most commonly used ${ }^{1}$ the line capacity is assumed to be concentrated at one point, or for longer lines, the capacity is divided into several parts and these several capacities are connected across the line at various points. The pressures consumed over the line are then added geometrically to the receiver pressure. In the second method-involving hyperbolic functions-the algebraic results are worked out for distributed capacity. Both these methods are open to objection:

The first because for long lines-75 to 150 miles-it is quite laborious. The second method, while it is accurate and would be the only method to use if our transmission lines were several hundred miles in length, has the disadvantage that the equations come out in such form as to be practically meaningless to any but trained mathematicians. Most men do not like to use formulæ blindly: that is, formulæ which cannot be analyzed and each term given some physical meaning are not popular with practical men.

The method here given is a modification of the first mentioned, and will be found to give results, for distances up to 200 miles and possibly 300 , as accurate as we could get by actual measurements on the completed line with the best instruments at present available for measuring alternating currents. Only one assumption is made that is not absolutely correct: The charging current per unit length of line is the same at all points of the line.

The error involved in this assumption can be very easily determined. The rise in voltage-with receiver circuit open-over a transmission line about 60 miles in length, and about $30^{\prime \prime}$ between wires, is about one per cent. at 60 P. P. s.; the percentage rise being practically independent of the voltage applied to the line. The percentage rise in voltage varies, as will be shown, practically as the square of the length of the line and the square

1 See "Alternating Current Phenomena," by C. P. Steinmetz, p. 153. 
of the frequency. For the same frequency there will be a rise of about $4 \%$ over a line 120 miles long. This means, of course, that the charging current per unit length of line will be $4 \%$ greater at the receiver than at the generator. The percentage rise in voltage if this extra current be taken into account will be less than

$$
\varepsilon<4 \%(1+.04)<4.16 \%
$$

That is, the error made is less than .16 of one per cent. of the line pressure. The error will reach one per cent. when the transmission line has a length of about 200 miles.

Aside from the above the regulation of step-up and step-down transformers and generator enter the calculations for the regulation of the system, and since the self-induction of these is usually several times larger than the line of self-induction and is known only approximately-especially the generator self-induction-itis needless to strive for great accuracy in the line calculations.

From the above considerations it will be evident that for an open-circuited line the charging current may be considered the same at all points of the line.

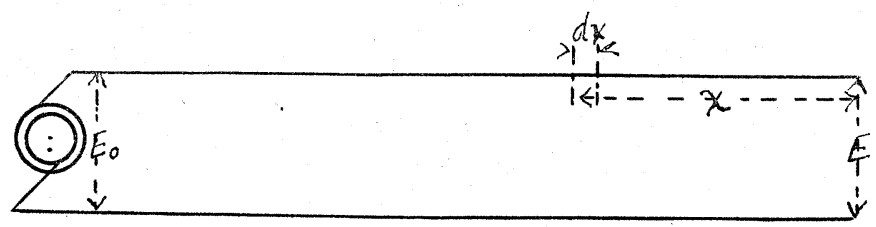

Fia. 6.

In Fig. 6. let

$r=$ resistance per unit length of line.

$l=$ self-induction per unit length of line.

$c$ = capacity " " " "

$i$ = charging current " " "

$E_{0}=$ Е. м. F. at terminals of generator.

$E=$ receiver к. м. $\mathbf{F}$.

$\omega=$ frequency.

$L=$ Total length of line.

The charging current crossing the element of line $d x$ at distance $x$ from the receiver is

$$
i_{\mathrm{x}}=-E j c \hat{x} \omega
$$

$\left(-j\right.$ is an operator to show that the current is $90^{\circ}$ in advance of the pressure.) 
The E. M. F. $d e$ consumed by the element of line $d x$ is (receiver open-circuited)

$$
d e=-j E \operatorname{Ec} \omega(r-j l \omega) d x
$$

Integrating this between the proper limits we get

$$
\begin{aligned}
e & =-j \frac{i x^{2}}{2}(r-j l \omega) \\
& =-j \frac{i x}{2}(r x-j l x \omega) \\
& =-j \frac{I_{\mathrm{c}}}{2}(R-j L \omega)
\end{aligned}
$$

In the last equation, $I_{\mathrm{c}}$ is the charging current, $L$ is the selfinduction, and $R$ is the resistance of the total length of line.

From equation (11) we see that if the charging current were the same for each unit length of line it would be mathematically correct to assume the line capacity concentrated at the center of the line, that is, at the center of gravity of the capacity load.

The percentage rise of potential will be practically equal to

$$
\varepsilon=\frac{C \omega L \omega 100}{2}
$$

in which $C$ is the total capacity of the line. $C$ and $L$ are proportional to the length of line, and hence, the percentage rise in potential varies practically as the square of the length of line and the square of the frequency.

From equation (11) we get for the generator pressure

$$
E_{0}=E+e=E-j \frac{I_{\mathrm{c}}}{2}(R-j L \omega)
$$

As has been shown, $I_{c}$ may be calculated by the equation

$$
\begin{aligned}
& I_{\mathrm{c}}=\mathbb{E} C \omega \\
& I_{\mathrm{c}}=E_{0} C \omega
\end{aligned}
$$

without appreciable error in the result of the percentage rise in pressure. 
Graphically, equation (12) is as represented in Fig. 7.

$o a=E$ receiver.

$a b=-j \frac{I_{\mathrm{c}} R}{2}$.

$b c=\frac{-I_{\mathrm{c}} L \omega}{2}$

$o c=E_{0}$ at terminals of gènèrator.

Suppose, now, we consider the receiver circuit loaded, and calculate the error made by assuming the charging current the same at all points of the line. Let the generator pressure be $p$ per cent. higher than the receiver pressure, that is,

$$
E_{0}=E\left(1+\frac{p}{100}\right)
$$

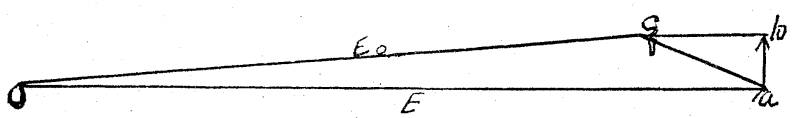

FIG. 7.

and assume that the potential along the line falls on a straight line from generator to receiver. (The true error will be less than that calculated with this assumption, since the pressure falls more rapidly at the generator than at the receiver.)

The charging current per unit length of line at a distance $x$ from the receiver circuit will be

$$
i_{\mathrm{x}}=i\left(1+\frac{p x}{L 100}\right) x
$$

( $L$ is the total length of line; $i$ is the charging current at receiver circuit.)

Suppose the angle of lag of the receiver load to be $\theta$, then, the total load current may be written

$$
I=I \cos \theta+j I \sin \theta .
$$

The current crossing the element of line $d x$ is

$$
I_{\mathrm{t}}=I \cos \theta+j I \sin \theta-j i\left(1+\frac{p x}{L 100}\right) x .
$$


The E. M. F. consumed by the element of line $d x$ is

$$
d e=\left[I \cos \theta+j I \sin \theta-j i\left(1+\frac{p x}{L 100}\right) x\right](r-j l \omega) d x
$$

Integrating, we get for the 上. м. F. consumed over the line

$$
\begin{aligned}
e=I \cos \theta(R-j L \omega) & +j I \sin \theta(R-j L \omega)- \\
& j \frac{I_{\mathrm{c}}}{2}\left(1+\frac{p}{3 \times 100}\right)(R-j L \omega)
\end{aligned}
$$

The percentage rise due to charging current will be less than

$$
\varepsilon=\frac{C \omega}{2}\left(1+\frac{p}{3 \times 100}\right) L \omega 100 .
$$

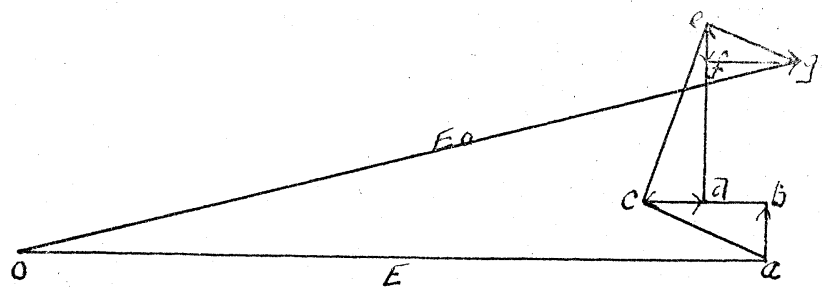

Fig. 8.

If we take $C \omega \times \frac{L \omega}{2} \times 100=4$, that is, a line about 120 miles in length, and give to $p$ a value as high as 20 -the generator pressure is $20 \%$ higher than the receiver pressure-we get

$$
\varepsilon=4 \%\left(1+\frac{20}{300}\right)=4 \%(1+.06)=4.24 \% \text {. }
$$

The error made by assuming charging current constant is about one-fourth per cent. of the line pressure.

It is evident, then, that either for a loaded or unloaded line the charging current may be considered constant. Equation (13) may therefore be written $e=I \cos \theta(R-j L \omega)+j I \sin \theta(R-j L \omega)-j \frac{I_{\mathrm{c}}}{2}(R-j L \omega)$.

The pressure at generator terminals is $E_{0}=E+e$

$=E+I \cos \theta(R-j L \omega)+j I \sin \theta(R-j L \omega)-j \frac{I_{\mathrm{c}}}{2}(R-j L(\omega)$. 
This equation is represented graphically in Fig. 8.

$$
\begin{aligned}
& a b=-j \frac{I_{\mathrm{c}} R}{2} . \\
& b c=-\frac{I_{\mathrm{c}} L}{2} . \\
& c d=+I \cos \theta R . \\
& d e=-j I \cos \theta L \omega . \\
& e f=+j I R \sin \theta . \\
& f g=+I L \omega \sin \theta .
\end{aligned}
$$

Instead of combining the currents geometrically as we pro. ceed from receiver to generator we see that we may consider each

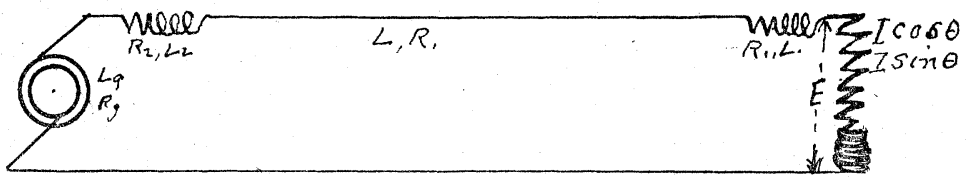

Fig. 9.

component of the receiver current as flowing over the entire line impedance, and the capacity current as flowing over the impedance from the center of the line to the generator. Looking at the matter from this point of view the E. M. F. at the terminals . of the generator, or the total E. M. F. generated, may be at once written out for any line.

Let in Fig. 9.

$$
\begin{aligned}
& R_{1}=\text { equivalent resistance of step-down transformers. }{ }^{1} \\
& R_{2}=\text { " " " step-up transformers. } \\
& L_{1}=\text { " self-induction of step-down. } \\
& L_{2}=\text { " " " " step-up. } \\
& R g=\quad \text { " " resistance of generator. } \\
& L g=\quad \text { " self-induction of generator. } \\
& R=\text { resistance of line. } \\
& L=\text { self-induction of line. }
\end{aligned}
$$

$1 \mathrm{It}$ is customary to convert all pressures to equivalent full-line pressure. If $r_{1}$ is the resistance of primary transformer and $r_{2}$ the resistance of the secondary, the equivalent resistance $R_{1}$ is calculated by the formula

$$
R_{1}=r_{1}+r_{2} n^{2}, n \text { being the ratio of transformation. }
$$

The equivalent self-induction of transformers is determined from the ohmic pressure-drop and the short-circuited regulation. 
Also let

$$
\begin{aligned}
& L_{\mathrm{t}}=L_{1}+L_{2}+L_{\mathrm{g}}+L . \\
& R_{\mathrm{t}}=R_{1}+R_{2}+R_{\mathrm{g}}+R .
\end{aligned}
$$

The E. M. F. generated is

$$
\begin{gathered}
E_{\mathrm{g}}=E+I \cos \theta\left(R_{\mathrm{t}}-j L_{\mathrm{t}} \omega\right)+j I \sin \theta\left(R_{\mathrm{t}}-j L_{\mathrm{t}} \omega\right)- \\
j I_{\mathrm{c}}\left(\frac{R}{2}+R_{2}+R_{\mathrm{g}}\right)-j\left(\frac{L}{2}+L_{2}+L_{\mathrm{g}}\right)
\end{gathered}
$$

The figure representing this will be similar to Fig. 8. Each component current is represented by the pressure triangle corresponding to the impedance over which that current flows. That is, each component current may be considered as producing the same effect as though no other current flowed over the line. The advantage of this way of looking at the matter is that we see by a glance at the equation or the figure how a change in any component current will affect the pressure relations of receiver and generator. To illustrate this, let us assume the load to remain constant and determine how the generator pressure must vary to give constant receiver pressure for any change in power factor of the load.

The charging current remains constant; therefore, the triangle A B C, Fig. 8, does not change in magnitude or position. Since the load is assumed constant, the value $l \cos \theta$ is constant and, consequently, the triangle $\mathrm{O} D \mathrm{E}$ does not change. The only variables are $I$ and $\sin \theta$. We have, however,

and

$$
\begin{gathered}
E I \cos \theta=W(\text { a constant) } \\
I=\frac{W}{E \cos \theta}
\end{gathered}
$$

$$
I \sin \theta=\frac{W \tan \theta}{E} .
$$

The triangle E F G always remains similar to triangle o D E. The point $g$, therefore, moves on the straight line $e g$ (if the load current is leading, e $g$ must be drawn in the opposite direction) for variable power factor. The length $e g$ increases directly as $\tan \theta$ and is drawn at right angles to $c e$. 
Equation (14) may be solved for $E_{\mathrm{g}}$ algebraically most easily by writing

$$
\begin{aligned}
& E_{\mathrm{g}}=\left[E+I \cos \theta R_{\mathrm{t}}+I \sin \theta L_{\mathrm{t}} \omega-I_{\mathrm{c}}\left(\frac{L}{2}+L_{2}+L_{\mathrm{g}}\right) \omega\right] \\
& -j\left[I \cos \theta L_{\mathrm{t}} \omega-I \sin \theta R_{\mathrm{t}}+I_{\mathrm{c}}\left(\frac{L}{2}+L_{2}+L_{\mathrm{g}}\right) \omega\right]
\end{aligned}
$$

and adding the terms in the square brackets before taking the square root of the sum of the squares. Laid out on paper to a large scale it will be found that results sufficiently accurate for most practical purposes can be obtained with a small amount of labor. Another advantage of the graphical method is that it presents to the eye a picture of the entire circuit.

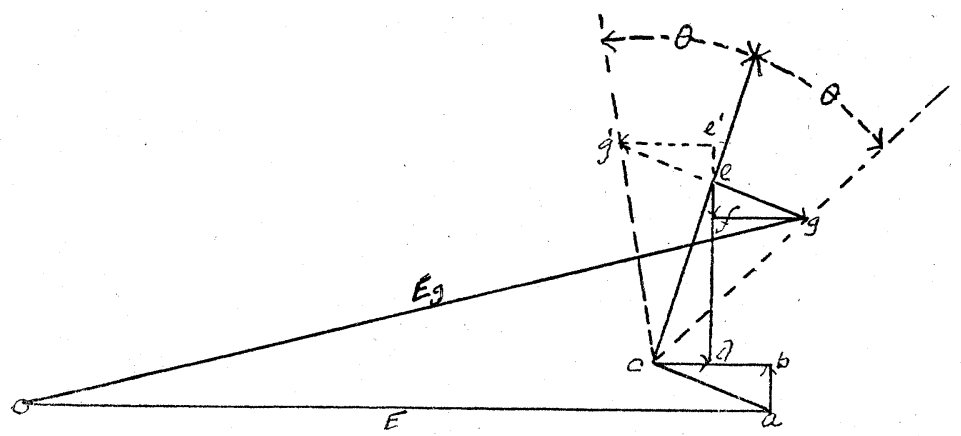

Fig. 10 .

The method of finding the regulation for variable load and constant power factor is shown in Fig. 10.

The magnitude of $c e$ is proportional to $I$, that is, proportional to the load for constant power factor, since

$$
c e=I \cos \theta\left(R_{\mathrm{t}}-j L_{\mathrm{t}} \omega\right) ;
$$

the magnitude of $e g$ is proportional to the load also, since

$$
e g=j \frac{W}{E} \tan \theta\left(R_{\mathrm{t}}-j L_{\mathrm{t}} \omega\right)
$$

$\bullet g$ is always drawn at right angles to $c e$. The triangles $c d e$ and $e f g$ are always similar and for constant power factor increase in the same ratio. While the point $e$ moves along $c e$, the 
point $g$ moves along $c g$, the line $c g$ making an angle $\theta$ with $c e$. If the current leads by the angle $\theta$ the locus of $g$ will be along the $0 g .^{\prime}$

In Fig. 11 the arc of a circle has been drawn with 0 as center and $o, 0$ as radius. If the receiver pressure is to remain constant with constant generator pressure, the locus of $g$ must be on the arc of this circle.

If there is an inductive receiver load the regulation will be very unsatisfactory unless $f g$, Fig. 10 , decreases more rapidly than $c d$ increases. $c d$ increases with the load, $f g$ increases or decreases as

$$
\frac{W}{E} \tan \theta
$$

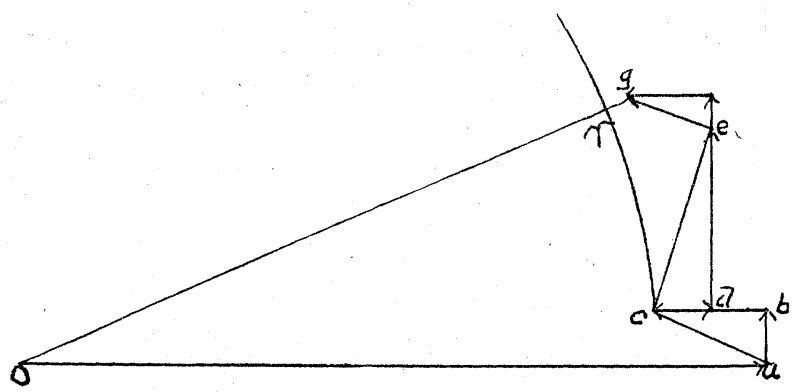

Fig. 11.

increases or decreases. On an induction motor, as the load increases the lag decreases, therefore, a load of this kind after starting does not interfere very much with good regulation. The regulation of the receiver for constant pressure is most difficult when we have a synchronous motor which is carrying a variable load, such as a street railway load.

It is seen from Fig. 11 that in order to keep the receiver pressure constant the leading component of current $I \sin \theta$ must increase as the load increases or $\theta$ must change from lag to lead. This can, of course, be done when a synchronous motor is running a street railway generator by putting a shunt and series winding on the field of the motor. For the sake of economy $\theta$. is usually changed from lag to lead as the load increases by under-exciting the motor for loads below the average load, and 
over-exciting for loads above the average. In Fig. 12 suppose

$$
I \cos \theta\left(R_{\mathrm{t}}--j L_{\mathrm{t}} \omega\right),
$$

which is proportional to the power intake of the motor, is represented by the triangle $c e$ at full load, by $c e^{\prime}$ at average load and by $c e^{\prime \prime}$ at no load. With $o e^{\prime}$ as radius draw with 0 as center the arc of a circle through $e^{\prime}$. Then at full load the motor must be over-excited so that the length

$$
e g=I \sin \theta\left(R_{\mathrm{t}}-j L_{\mathrm{t}} \omega\right)
$$

will reach the circle. Similarly at no load the motor must be under-excited so that $e^{\prime \prime} g^{\prime \prime}$ will reach the circle.

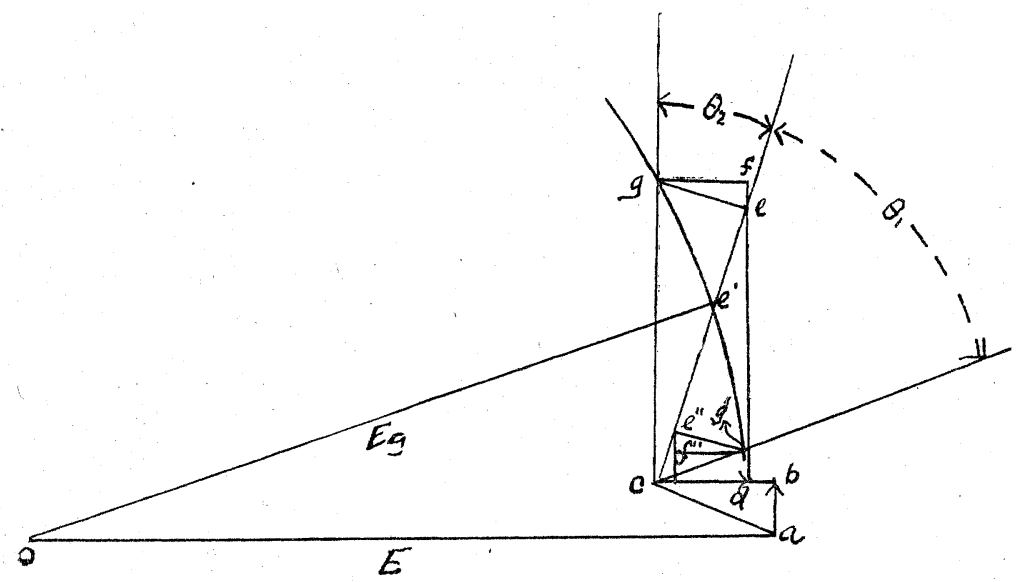

Fre. 12.

By laying off the pressures to a large scale the angles $\theta_{1}$ and $\theta_{2}$, Fig. 12, by which the current must lag and lead at no-load and full-load respectively, may be very closely determined. From the eonstants of the motor it will be possible by the aid of the synchronous motor diagram to determine the excitation for noload and full-load to give constamt receiver-pressure with constant generator-pressure. The motor may then be run as a generator and the no-load excitation set to the value determined. The current in the series field coil corresponding to full-load on the motor could next be adjusted by the series field shunt until the pressure developed by the motor as a generator corresponded to the full-load excitation as found above. The motor would 
then carry its load without causing much variation in the receiverpressure. It is necessary to know only the no-load power of the motor and the self-induction and resistance of the entire circuit including that of the generator and motor.

\section{Some Transmission Line Troubles.}

At the end of the two-phase forty-mile transmission line there were in operation two shunt-wound synchronous motors, $100 \mathrm{K.w}$. and $50 \mathrm{K.w.}$., running street railway generators. It was found that these motors behaved very badly at no-load and not all satisfactory at all loads.

At no-load the motors would take almost full-load current and were very unstable, falling out of synchronism for a sudden small increase of load. At about full-load the current would be but little above what it ought to be and the motors became more stable. Changing the excitation of the motors did not improve their action. The following readings taken on the 100 к. w. motor at no-load may be of interest.

(Instruments in one-phase.)

\begin{tabular}{|c|c|c|c|c|c|c|}
\hline$I$ & $E$ & $W a=I E$ & $W$ & $\operatorname{Cos} \theta$ & $\theta$ & Excitation \\
\hline 18.2 & 111.5 & 20.2 & 10 & 0.49 & $60^{\circ}$ & For min. cur. \\
\hline 18.4 & 113.5 & 20.9 & 10.4 & 0.49 & $60^{\circ}$ & " ، \\
\hline 19.3 & 110.9 & 21.4 & 9 & 0.42 & $65^{\circ}$ & “ \\
\hline 18.8 & 115 & 21.6 & 10.2 & 0.47 & $62^{\circ}$ & "6 ، \\
\hline 30 & 119 & 35.7 & 8 & 0.225 & $77^{\circ}$ & For min. watts. \\
\hline 20.8 & 116.5 & 24.2 & 11.2 & 0.47 & $62^{2}$ & " 6 \\
\hline
\end{tabular}

The measurements were made with Weston instruments that had been checked; the readings were taken on one phase and then on the other. The motors operated across a 2200-volt-line; the value of $E$ obtained by use of 20 to 1 multiplier. The fullload current should be about 22 amperes.

The 50-k. w. motor acted in a similar manner; the no-load current was 14 amperes. A water rheostat was connected in each phase of the $50-\mathrm{k}$. w. motor; with 8 ohms added the noload current was 12.2 amperes. The motor at this point dropped out of synchronism on adding a small length of shafting.

There was no "hunting" of the motors. Copper bridges were put in between the poles of one motor, but this did not improve its action. Since there was no hunting, the failure of the bridges to improve the action of the motor was predicted. The large no-load current was believed to be due to the difference of wave 
shape between generator and motor E. M. F's, the motors acting during part of a cycle as motors, and during the remainder as generators, sending energy back to the system. This explanation seemed to be the only possible one. The difference in wave shape of generator was believed to be due to the magnetizing action of the capacity current distorting the wave shape of the generators. As is well known, the effect of a capacity current is to flatten the E. M. F. wave, and may in an extreme case produce a "jagged" wave.

That the above explanation is the correct one was satisfactorily proved by taking off at the receiver-end of the line a lagging current to neutralize the capacity current. The secondary windings of two transformers were used as induction coils, the magnetic circuit of the transformers having been opened to increase the lag angle.

With the capacity current nearly neutralized it was found that the 100 -K. w. motor when running a piece of shafting took 11.5 amperes. The induction coils were then taken out and the motor current increased to 23 amperes, and could not be reduced by changing the excitation. The $50-\mathrm{K}$. w. motor drew 13 amperes per phase at no-load with the induction coils out and 3 amperes with the coils in. With the coils neutralizing the capacity current the synchronous motors would not fall out of synchronism.

The variation in voltage at the receiver station was about $10 \%$ when the'synchronous motors were running the railroad without the induction coils, and about $3 \%$ under the same conditions as to load but with the induction coils taking enough current to neutralize the capacity current. This $3 \%$ variation of receiver voltage was nearly all due to the change of speed of the waterwheels. 


\section{DISCUSSION.}

The President-Gentlemen, the paper is now open for discussion.

Mr. Steinmelz :-Mr. President, with your permission I desire to say a few words regarding this extremely interesting paper. I do not see any reason for using two letters when a single letter can be used. I would leave the Omega out and put in the Standard letter. But that is a minor matter.

Dr. Perrine:-It was done to show where the $l$ came from which previously we had worked out.

Mr. STEINMETZ:-This shows the capacity of the line; and something very important is the condition found in power transmission, but to a certain extent it is of secondary importance; that is to say, it is not so essential to calculate the extent of capacity accurately, but with approximation; and in most cases almost any approximation will do. What is necessary is rather to determine the limiting value of the effect of capacity, to see whether this effect is of sufficient amount to require a more accurate investigation; and as a rule we find it is not. Here in this very long transmission, while it is considerable, it is not of such importance as to require a very accurate determination of its effect. The only case of which 'I know where the capacity is of considerable magnitude is probably the transmission of $\mathrm{my}$ friend Mr. Nunn; and this is considered due to the very high voltage and the comparatively small amount of power; and my friend $\mathrm{Mr}$. Nunn told me had obtained some valuable information.

There is one further remark I would like to make regarding the last experience referred to by the speaker, in these synchronous motors taking excessive current. Now it is quite possible that wave-shape had something to do with this, but I am not quite sure of that, for somehow or other, I do not really believe much in the waveshape. While wave-shapes are very important theoretically. I have never yet found any case where any difficulty could be traced to the wave-shape without any donbt -without permitting any other explanation. On the other hand, there are many cases where disturbances have been observed, and explanations made for it by the wave shape, but after being investigated they were found not to have anything to do with it. In one case of a converter the current increased out of all proportion as the load came on, and I found somebody made a very ingenious explanation of how that was due to the wave-shape; but I sent one of $\mathrm{mv}$ assistants there, who did not believe in wave-shape, and after carefully looking over it he found the series field reversed. and so the armature had to magnetize the field. Now, in coming to this particular instance here, it may be the wave-shape, but I think there is possibly a different explanation, though I cannot say which is accurate, the real 
reason being that I am not sufficiently familiar with the conditions. If you take a transmission line equal in length to onefourth of the wave--a one-fourth wave-length-and then impress a constant electromotive force at the generator end of the line, you will get at the receiving end a constant current. The transmission line has such capacity or induction as will be one-fourth of the wave. [Illustrating]. If the length is exactly this, whatever apparatus you put at the receiver end it will always take the same current. This is an extreme case, but even with a line very much shorter than that, as soon as the length of the line increases to a certain extent by the effect of the capacity and selfinduction, there is such an effect at the receiving end as tends to regulate for constant current. A very frequent case, the shunting of an induction motor at the receiving end of the line, or a shunting of a self-induction coil, will throw the selfinductive capacity of the system sufficiently out of balance to spoil this tendency to constant current regulation. I do not know whether this is a condition existing here or what else the condition was. What I want to say is that from the data given here we are not entitled yet, I think, to conclude that the wave. shape had anything to do with the phenomenon, and I should rather believe that the wave-shape had nothing to do with it.

Dr. Perrine:-Before Mr. Steinmetz sits down-I confess I am very nearly as much a disbeliever in wave-shapes as Mr. Steinmetz is, but I have been faced by this problem. Starting with the generator unloaded, there was a motor current of 23 amperes. With a lagging current of 18 amperes at the receiver the motor current dropped to $11 \frac{1}{2}$ amperes; and Mr. Steinmetz cannot say that there is anything the matter with the motors, because they are his own motors.

Mr. Steinmetz:-The only suggestion I would make of that, is inserting self-induction.

Mr. BAUm:-Mr. President, Mr. Steinmetz in his last remarks has given, in another way, our explanation; that is, instead of saying the excessive motor current was due to wave-shape, suppose we say it was due to "hunting" at 60 cycles per second. That means exactly the same thing. In our paper we say the motor during part of the cycle acted as a motor and during the remainder of the cycle as a generator. Does not that mean the same thing as saying that it was "hunting" (electrical hunting) at 60 crcles per second? In the motor we believed there was a triple frequency current, and on that assumption went to work to cure the trouble. The General Electric Co.'s engineer out there did not agree with us ; like Mr. Steinmetz, he said it was "hunting." He wrote back to the main office and sent all our measurements; they sent back a report that it was "hunting," and sent out bridges to put in between the pole tips of the motor -the usual cure for "hunting." . We predicted that the bridges would not cure the trouble. The fact is that the bridges had no 
effect whatever to reduce the motor current. Then to show that our explanation was the correct one we threw in the induction coils and the motor current immediately dropped, in one case one-half, and in the other from 14 to 3 amperes, and could then draw leading or lagging current by varying the excitation. Before that we could do nothing at all with the excitation to reduce the current taken by the motors.

Dr. Kennelly:-Mr. President and gentlemen. We started with a paper on aluminium, and aluminium is so light that we got into the airy fields of mathematics; and with your permission I beg to say a few words now about aluminium and the wire, because the task fell to my lot to make measurements of samples of the wire, and I examined about a hundred samples and made as careful tests as I could upon its electrical and mechanical properties. The electrical properties were very nearly uniform. There was very little difference between the electrical conductivity of any of the lots that I had occasion to examine, and this appeared to be due to the relatively high degree of purity of the wire and the absence of admixture or alloy. The fracture of the wire always assumes a characteristic form and terminates in a peculiar nipple at each side of the break. I think that if the wire were defective it would be more likely to break off flush. With steel wire there is a small, steady, elastic elongation until you get beyond a certain limit, and then the permanent elongation increases very rapidly; but in the case of aluminium wire, you cannot assign any particular point at which the elastic limit can be said to lie. All you can say is that the stress shall not exceed a value at which the elongation shall be appreciable; and from the statements that have been made to us in the paper, it seems that there is no difficulty in arriving at that point in practice.

Dr. ' 'errine:-We derived that from your curve

Dr. Kennelly:-In regard to the determination of the pressure at the receiving end of a line, if the capacity of the circuit is assumed as collected together into one condenser and located in the centre of the line, the assumption is quite good enough for most practical cases, namely, a case of low frequency on a line not greater than 200 miles in length, and with ordinary capacity and inductance of overhead copper conductor, but you may have cases of short wires with exaggerated capacity or inductance, and in cases of high frequency you will be unable to obtain sufficient accuracy; and in such cases I believe in the use of hyperbolic functions. I don't think there is any difficulty in using them after a few trials.

I want to make one humble protest against the use of what I think is an inversion, or what I will submit is an inversion of the direction of reactances, geometrically. I see the reactances in this paper are all written $r-j x$, and, as a mere matter of convention, I would submit that that is undesirable. It is not a 
question of what is right or wrong. If you accept the notation, it is all right. I have always maintained that the reactance of a reduction coil should be written $r+j x$. I have the honor to differ upon this point with Mr. Steinmetz, who, I think, is responsibleI am not sure, but I think he is responsible-for introducing negative reactance, and $I$ think he justifies his position upon astronomical grounds. I am quite ready to sacrifice my view if it should be generally agreed that reactance should be measured negatively and a condenser measured positively, and with a lagging current which should be measured in that direction. But, in trigonometry, we always measure angles positively in the counter clockwise direction, and a negative lag angle should be in the negative direction. I think it would be a good plan to bring that matter up and have a consensus of opinion. Whenever I read Mr. Steinmetz's mathematics, I have to stand on my head in order to understand the reactances.

Mr. Steinmetz:- - Having been challenged regarding these formulæ, I may give my reason for having adopted them. It is not based on astronomical reasoning. Astronomical reasons led me to adopt the counter-clockwise direction. The reason it happened to be minus in my case and plus in another, in the method of graphic representation, it is nothing but a symbolic method of graphical representation. Long before anybody thought of electrical engineering, polar co:ordinates were used, with the time as angle or amplitude, and the instantaneous value as vector. Now, somehow or other, when graphical representations were first introduced-they were introduced by Kapp, I think, and othersthey seem not to have thought of the familiar system of polar ordinates, but discovered and invented a different method of representation. They chose a line representing the maximum value of the current, and they let that line rotate around, and a projection of this line represented the instantaneous value. It is a very interesting method, and it has been introduced to a certain extent; the only objection is, that a better representation has been known in the common polar co-ordinates since a few centuries. Here is the sketch of Dr. Kennelly. In his representation, this current is lagging behind the electromotive force, because if he takes his line and revolves it around it comes there later. But if you represent it, not by some artificial method but by the standard polar co-ordinate system, then we denote the electromotive force by the diameter of its polar-circle. If the current is lagging, the maximum value of the current will be reached at a later time. So these signs depend upon the graphical method you choose in starting. You may use a polar system, which is used in all engineering branches, as, for instance, in giving the valve motion of steam engines, or you may choose some special method not used anywhere else.

The President:-Is there any further discussion? Mr. Nunn, I believe, has had considerable experience with aluminium lines, and we shall be very giad to hear from him. 
Mr. Padl N. Nunn.-The question of aluminium lines is one of a great deal of interest, I believe, to all who have long distances to reach, especially where the distances are euch and the conditions such as to permit of the use of quite high pressure. I do not believe that I have anything to offer the INsTITUTE this morning upon the question under discusion. The questions involved are pretty complicated. I am not prepared to offer a word on the authentic evidence given this morning. I have found a great deal of difficulty in satisfying myself of just the conditions which would obtain upon the erection of long aluminnium lines, and while I suppose the information at hand, with most of us, is sufficient to determine pretty closely, within 1.5 per cent., I think that is near enough. We are interested in those practical results, but closer than that I think it is a question of scientific interest very largely, and a great many of us are not prepared to go into such a question to the extent necessary, simply on the ground of scientitic interest. Our observations of the use of aluminium are very interesting, but I do not know that there is anything in it to throw a particle of light on the question as discussed here this morning. "I may say that $I$ think we are in a position to second the statement which has been made that the alloyed aluminium, or certain alloyed aluminium, is ngt safe. I do not think this should perhaps be expressed too generally. There is a line in very successful operation, I understand, and I cannot learn that there has been a particle of trouble from it, in which the alloy is very considerable, put in very carefully; but the common alloyed aluminium, which I believe instead of being alloy is impure aluminium, handled under the brand of $\mathrm{XX}$ and $\mathrm{BB}$ or something like that, is defective because it is not homogeneous. The Institute might be interested in knowing that in about six miles of a certain aluminium circuit which we erected something over a year ago, during the first month of its erection, I cannot say use, it broke, an average of every 100 feet in length, or every span. There were tifty-two breaks to a mile in a month. It took the services I believe of four men all the time to repair breaks. We simply let that go on, to see how long it would continue. We do not know; we finally stopped it. 'There were but four breaks in that six miles which showed an elongation of $2 \%$-enough elongation so that the eye could distinguish it; and in several cases I noticed something which appeared like a physical defect, a sliver, along the side, which showed something in the way of drawing; it was rough; the appearance was somewhat crystalline, and apparently it had broken exactly as a piece of glass would break, that is, square. We photographed some of these ends and sent them to the Pittsburgh Reduction Company, and I think the trouble was under:tood the moment they saw the photographs. There was only one condition under which that could occur - the case of an ingot in which the impurity or alloy was not thoroughly mixed and did not produce a 
homogeneous mass. It seems to me as if in the process of drawing, that impurity settles in the form of an infinitely thin stratum through the wire and that under conditions of moderate stress, probably in our case seldom exceeding 1,500 pounds to the square inch, it is attended with vibratory results. We have replaced much of this line, practically all, with pure aluminium, stranded, and liave not had a particle of trouble. I think the question of resistance in joints is one with which we must labor for some time to come. I have learned that aluminium deteriorates particularly in a country where it is subject to alkalies, or to what is termed corrosive salt. The series of joints, which were at first very promising, afterwards became quite troublesome.

Dr. PERrine:-I would like to reply to one or two of these points that have been made. In regard to the elastic limit that Dr. Kennelly describes; from the curve which he gave here to-day we determined the strain that it would be safe to allow, and it was found to be satisfactory. I examined a large number of the breaks from the lines that were giving the most trouble, and found that in every case they were exactly as Mr. Nunn described them. The break is a shear, a sharp break, with a reduction of area on one side simply, which is the characteristic break of imperfectly alloyed wire. I have had a good deal of experience with imperfectly alloyed wire while trying to make silicon bronze, and the breaks were of that character; and almost all imperfectly mixed alloys will give that sharp break without any reduction in area. There is apparently a break from the wire falling. and getting a slight reduction of area on the under side and then shearing square across; it is not a break that is characteristic of aluminium any more than it is of any other imperfectly alloyed material. I take that characteristic of the break as one reason for saying these are imperfect alloys ; and the other reason mentioned in the paper is that one of the lines which we had an opportunity to test gave trouble on one-half of the line and the other half gave no trouble at all. There were three breaks in one-half of the line due to short-circuit, or something falling across the line; and in the other half of the line there were 30 breaks a month, and that over its entire length, although it was said to be the same sort of wire The resistance of the whole line showed the wire to have only 90 per cent. electrical conductivity. This could not he due to hard drawing. By hard drawing you might get one or two per cent. resistance increase, but 10 per cent. increase must necessarily mean an alloy. The peculiarity of the elastic limit is not different from the peculiarity of the elastic limit of metals in the same group as aluminium, and in that respect copper groups with aluminium. In hard-drawn copper we have such a small percentage of elongation before breaking, but I have never yet seen any one who was able to draw the curve for the elongation of copper; but when we break soft-drawn copper we find it proceeds almost exactly as the aluminium was found to elongate in this case. It 
is a general idea with many metallurgists that hard drawing does not change the relative position of the elastic limit. As regards these points there seems to be nothing new that aluminium has introduced into the art of metal working. It is simply that, being a metal that is liable to irregularities, it must not be used unless it is carefully inspected. I attribute our success in this line more to the careful inspection which Dr. Kennelly gave to the metal before we put it up than any other thing.

As regards the question of the signs of the complex quantities I thoroughly agree with Mr. Steinmetz. I studied complex quantities long before I studied alternating or direct currents. After I had studied complex quantities I began to study rectangular coordinates. The angle of lag seemed to me to be always the other way. It seems to me the system which Mr. Steinmetz developed is a rational system, and the only unfortunate thing is the man who has reached one system does not dare to touch a paper written by the man who has written in the other system.

The Secretary :-There will be a collation served in this building at about one o'clock, and after that the remaining papers will be taken up. Professor Rowland will be very happy to have the members, after the collation or at any time, look about this building. It is very interesting. He has circulars describing the various courses given at the Institute, which may be had at the Secretary's office in the lobby.

Mr. Dunn :-Mr. President, our Secretary's announcement of the collation reminds us of the very many courtesies that have been extended to us by the Reception Committee and by our brethren in Philadelphia, and if hospitality is one of the cardinal virtues it is certainly proper to acknowledge it. I am not sure but that in the motive of iny remarks there is something in the nature of the expression by an old cynic, that gratitnde is a desire for future favors. But be that as it may, 1 am sure that our experience here in Philadelphia has been so pleasant that we all desire such future favors and hope it will be soon when we shall again come here. I would therefore nove that a committee be appointed by the Chair to draw up suitable resolutions acknowledging these courtesies and hospitalities which have been extended to us, and expressing in corporate action the same acknowledgment and thanks which have already been made by us individually. I am sure in speaking in this way I am voicing the sentiment of every member of the Institute who has attended this general meeting.

The resolution was carried and the President appointed as such committee, Calvin W. Rice, George F. Sever, and W: W. Ker.

The President :-The next paper is entitled: "A Practical Transmitter using the sine Wave for Cable Telegraphy; and Measurements with Alternating Currents upon an Atlantic Cable," by Dr. A. C. Crehore and Capt. G. O. Squier. 